\title{
Eplerian Philosophy for a New Way of Life for Health, Vitality, and Happiness
}

\author{
Gary R. Epler \\ Pulmonary and Critical Care Medicine, Harvard Medical School, Boston, MA, USA \\ Email: gepler@bwh.harvard.edu,garyepler@gmail.com
}

How to cite this paper: Epler, G. R. (2020). Eplerian Philosophy for a New Way of Life for Health, Vitality, and Happiness. Open Journal of Philosophy, 10, 187-191. https://doi.org/10.4236/ojpp.2020.102013

Received: February 18, 2020

Accepted: April 13, 2020

Published: April 16, 2020

Copyright $\odot 2020$ by author(s) and Scientific Research Publishing Inc. This work is licensed under the Creative Commons Attribution International License (CC BY 4.0).

http://creativecommons.org/licenses/by/4.0/ (c) (i) Open Access

\begin{abstract}
Too many people throughout the world are unhealthy, stressed, and disconnected from the community because they spend too much time being angry or in fear, and too much time having self-centered thoughts and judging others. People are not being their true selves. The Eplerian Philosophy based on brain science is defined as "know who you are moment by moment." This means know the brain region at any given moment and learn to quickly leave the unhealthy brain regions. The less time people think about themselves, the more they become their true selves.
\end{abstract}

\section{Keywords}

Eplerian Philosophy, Health, Community, Business, Productivity, Innovation, Amygdala, Cingulate

\section{Introduction}

Too many people worldwide are unhealthy, stressed, and disconnected from the community because they spend too much time being angry or in fear, and too much time having thoughts of self-criticism, self-pity, jealously, retaliation and taking from others. People are not their true selves. They're letting themselves be told who they are. They're trying to be someone else. If people are their true selves, then their anger and fear vanish in a moment. Their self-centered thinking is transferred to more productive and creative thoughts in a moment.

The concept of knowing who you are dates to ancient philosophers with the aphorism, "know thyself", inscribed in granite 3400 years ago. Socrates wrote "the unexamined life is not worth living", and Aristotle wrote "to know thyself is the beginning of wisdom" (LeDoux et al., 2018). This concept has survived thousands of years and has prompted several interpretations including knowing 
unconscious conflicts and the conscious self in the here and now (LeDoux et al., 2018), accurate self-appraisal (Krueger et al., 2011), and self-knowledge (Wilson 2009). But, what are the benefits?

Knowing who you are results in freedom. You don't need to listen to anyone. You're not controlled by anyone. You don't compare yourself to anyone. There is no need for blame, criticism, judgment or excuses. Yet, there are too few people that arrive at this point in their lives. Most people are trying to be the unattainable perfect person in their minds. They continue to judge others. This is unhealthy, unproductive and results in self-centered citizens. What is needed is an easy, reproducible method for people to "know who they are."

\section{The Eplerian Philosophy}

Brain science has shown many different independent brain regions (Hou et al., 2020; Kral et al., 2019; Le et al., 2019; Wang et al., 2019; Leong et al., 2018; Zhang et al., 2018; Oei et al., 2018) and people can only think from one brain region at a time. Thinking from some regions like the decision-making prefrontal cortex and creative-thinking frontal cortex result in healthy and productive outcomes. Sustained thinking from the amygdala anger region (Wang et al., 2018) and the posterior cingulate cortex self-thinking region (Brewer \& Garrison, 2014; Leech \& Sharp, 2014) result in poor health, decreased productivity, lack of innovation, and disconnection from the community.

The Eplerian philosophy is defined by seven words: "know who you are moment by moment." Using the limited "know who you are" is too general and so variable that it has been rendered meaningless. However, adding the three words, "moment by moment," adds accuracy and clarification to the concept. Everyone can know who they are at any given moment because everyone can know the brain region where the thoughts originate. Furthermore, people can learn to move out of the bad regions within a few seconds and into healthy brain regions. Anger and fear are everyday emotions, and if sustained for more than a few seconds, cause the stress-inflammatory response and ill health. People who learn to leave the cingulate region are healthier, more productive, more creative, enjoy life more, and are better citizens than counterparts who spend long periods of time thinking from the cingulate (Leech \& Sharp, 2014). Paradoxically, the less time thinking about yourself, the more you are your true self, i.e., know who you are moment by moment.

For people, the Eplerian philosophy is relevant for learning how to eliminate the harmful effects of emotional stress by managing anger, fear, anxiety, and sadness. The philosophy will help manage the stress caused by the many types of self-thinking including self-criticism, self-pity, resentment, jealously, revenge, judgment, and blame. Manage the stress by learning how to leave the amygdala anger center and the cingulate self-thinking center in a few seconds. Obtain the benefit of stress and eliminate the harm. There are several ways to stop thinking from these counterproductive regions. For example, feel the physical reaction to 
anger and fear for a few seconds excluding all other thoughts, let the emotional feelings peak, and the anger and fear will pass. Another way to leave these brain regions is to do the opposite behavior. Anger means something has been taken, e.g., pride, integrity, self-worth or autonomy; therefore, leave the amygdala anger center by doing the opposite, which is to give with expecting nothing in return. Give time, give energy, and give help. Cingulate thinking is also a "taking behavior" with blame, jealousy, resentment, and judgment; therefore, do the opposite by giving. For self-criticism and self-pity from cingulate thinking, self-compassion is the opposite. Be kind to yourself. Transferring out of these two brain regions in a few seconds will neutralize harmful health effects.

For business, the Eplerian philosophy protocol can be used for increased productivity and innovation by learning to quickly leave the amygdala anger region and the cingulate self-thinking center. Thinking from these primitive brain regions for more than a few seconds decreases productivity, performance, and creativity. Daily stress from too much work, deadlines, blame, and lack of control trigger the amygdala and cingulate regions causing elevated blood pressure, increased the heart rate, muscle tenseness, and shuts down the defense system and digestion. Uncontrolled stress leads to inflammation, heart disease, stroke, cancer, and a shortened life. Stress needs to be neutralized quickly before causing harm. Anger, fear, anxiety, and sadness are part of everyday life. Learn to extract the benefit of these emotions and neutralize.

The Eplerian philosophy model can be used for improved creativity and innovation at work. Learn to quickly stop thinking from the amygdala and cingulate regions and go to the creative brain region. For the best result, take the prefrontal cortex offline because thinking from this region is too judgmental and rigid for the free-thinking process needed for innovation. Remember the need to keep the creative brain region healthy for optimal innovation. The creative region and other positive brain regions are sensitive to unhealthy habits; and require eight hours of sleep, daily exercise, alpha-brainwave meditation time, and healthy nutrition. Learn the Eplerian philosophy for breakthrough innovation.

Additional applications of the Eplerian philosophy at work include improving the happiness level by learning to be content with the current situation moment by moment. This will promote positive social interaction between people where both individuals feel better after the connection.

For the community, application of the Eplerian philosophy will create trust and responsibility because people who know who they are moment by moment are not thinking from their amygdala anger region or their cingulate self-centered region. They can be trusted to know how they will respond in all situations and are responsible for themselves and others. People who know who they are moment by moment give and are willing to help. Improving trust and responsibility in the community will result in increased positive socialization resulting in reducing fear and a healthy community. 


\section{Conclusion}

The Eplerian philosophy is a model for people to know who they are moment by moment. People can learn to recognize the brain region that is originating their thoughts and learn to quickly leave harmful regions. Spending more than a few seconds in the amygdala anger region and the cingulate self-thinking region causes the cortisol stress response leading to unhealthy consequences, obtain the benefit of stress and neutralize. The Eplerian philosophy is for people to live their best lives at home, at work and in the community.

\section{Conflicts of Interest}

The author declares no conflicts of interest.

\section{References}

Brewer, J. A., \& Garrison, K. A. (2014). The Posterior Cingulate Cortex as a Plausible Mechanistic Target of Meditation: Findings from Neuroimaging. Annals New York Academy of Sciences, 1307, 19-27. https://doi.org/10.1111/nyas.12246

Hou, Y., Yuan, X., Wei, Q., Ou, R., Yang, J., Gong, Q., \& Shang, H. (2020). Primary Disruption of the Default Mode Network Subsystems in Drug-Naïve Parkinson's Disease with Mild Cognitive Impairments. Neuroradiology, 2020, 1-9. https://doi.org/10.1007/s00234-020-02378-Z

Kral, T. R. A., Imhoff-Smith, T., Dean, D.C., Grupe, D., Adluru, N., Patsenko, E. et al. (2019). Mindfulness-Based Stress Reduction-Related Changes in Posterior Cingulate Resting Brain Connectivity. Social Cognitive and Affective Neuroscience, 14, 777-787. https://doi.org/10.1093/scan/nsz050

Krueger, C. E., Rosen, H. J., Taylor, H. G., Espy, K. A., Schatz, J., Rey-Casserly, C., \& Kramer, J. H. (2011). Know Thyself: Real-World Behavioral Correlates of Self-Appraisal Accuracy. Clinical Neuropsychology, 25, 741-756. https://doi.org/10.1080/13854046.2011.569759

LeDoux, J., Brown, R., Pine, D., \& Hofmann, S. (2018). Know Thyself: Well-Being and Subjective Experience. Cerebrum, 2018, 1-15.

Leech, \& Sharp, D. J. (2014). The Role of the Posterior Cingulate Cortex in Cognition and Disease. Brain, 137, 12-32. https://doi.org/10.1093/brain/awt162

Leong, S. L., Vanneste, S., Lim, J., Smith, M., Manning, P., DeRidder, D. (2018). A Randomized, Double-Blind, Placebo-Controlled Parallel Trial of Closed-Loop Infraslow Brain Training in Food Addiction. Scientific Reports, 8, Article ID: 11659. https://doi.org/10.1038/s41598-018-30181-7

Le, T. M., Zhornitsky, S., Wang, W., Ide, J., Zhang, S., \& Li, C. R. (2019). Posterior Cingulate Cortical Response to Active Avoidance Mediates the Relationship between Punishment Sensitivity and Problem Drinking. The Journal of Neuroscience, 39, 6354-6364. https://doi.org/10.1523/JNEUROSCI.0508-19.2019

Oei, N. Y. L., Jansen, S. W., Veer, I. M., Slagboom, P. E., van de Grond, J., \& van Heemst, D. (2018). Stress Evokes Stronger Medial Posterior Cingulate Deactivations during Emotional Distraction in Slower Paced Aging. Biological Psychology, 135, 84-92. https://doi.org/10.1016/j.biopsycho.2018.02.018

Wang, Y., Zhu, Y., Chen, P., Yan, F., Chen, S., Li, G. et al. (2018). Neuroticism Is Associated with Altered Resting-State Functional Connectivity of Amygdala Following Acute Stress Exposure. Behavioural Brain Research, 347, 272-280. 
https://doi.org/10.1016/j.bbr.2018.03.021

Wang, Z., Hu, Y., Zheng, H., Yuan, K., Du, X., \& Dong, G. (2019). Females Are More Vulnerable to Internet Gaming Disorder Than Males: Evidence from Cortical Thickness Abnormalities. Psychiatry Research: Neuroimaging, 283, 145-153.

https://doi.org/10.1016/j.pscychresns.2018.11.001

Wilson, T. D. (2009). Know Thyself. Perspectives on Psychological Science, 4, 384-389. https://doi.org/10.1111/j.1745-6924.2009.01143.x

Zhang, Z., Yan, T., Wang, Y., Zhang, Q., Zhao, W., Chan, X. et al. (2018). Polymorphism in Schizophrenia Risk Gene MIR137 Is Associated with the Posterior Cingulate Cortex's Activation and Functional and Structural Connectivity in Healthy Controls. NeuroImage: Clinical, 19, 160-166. https://doi.org/10.1016/j.nicl.2018.03.039 